\title{
Adoption and Diffusion of Encoded Archival Description
}

\author{
Elizabeth Yakel and Jihyun Kim \\ School of Information, University of Michigan, 550 East University, Ann Arbor, MI 48109-1092. \\ E-mail: \{yakel, jhkz\}@umich.edu
}

\begin{abstract}
In this article, findings from a study on the diffusion and adoption of Encoded Archival Description (EAD) within the U.S. archival community are reported. Using E. M. Rogers' (1995) theory of the diffusion of innovations as a theoretical framework, the authors surveyed 399 archives and manuscript repositories that sent participants to EAD workshops from 1993-2002. Their findings indicated that EAD diffusion and adoption are complex phenomena. While the diffusion pattern mirrored that of MAchine-Readable Cataloging (MARC), overall adoption was slow. Only $42 \%$ of the survey respondents utilized EAD in their descriptive programs. Critical factors inhibiting adoption include the small staff size of many repositories, the lack of standardization in archival descriptive practices, a multiplicity of existing archival access tools, insufficient institutional infrastructure, and difficulty in maintaining expertise.
\end{abstract}

\section{Introduction}

Adopting and implementing new technologies is a complex process. In his seminal work on the diffusion of innovations, Rogers (1995) states that diffusion occurs within social systems-interrelated units sharing common goals, objectives, values, and practices (pp. 23-24). As such, the archival community in the United States forms a social system comprised of individual archivists, archival repositories in a variety of venues (e.g., colleges and universities, governments, businesses, religious organizations), professional organizations, and consortia. Increasing access to archival holdings has long been a shared goal within this community. The development of MAchine-Readable Cataloging (MARC) for archives and manuscripts and Encoded Archival Description (EAD) have provided two means for sharing descriptive information to achieve this goal. However, their utilization in the archival community is far from universal. The inconsistent adoption and lack of widespread diffusion of these standards has deep roots in the archival

Received February 20, 2004; revised July 13, 2004; accepted September 27, 2004

(C) 2005 Wiley Periodicals, Inc. • Published online 1 September 2005 in Wiley InterScience (www.interscience.wiley.com). DOI: 10.1002/asi.20236 social system where "a firm belief that since archives were unique, they required unique approaches and standards could thus never be applied" remains (Hensen, 1997, p. 286).

Encoded Archival Description (EAD) is an SGML/XML (Standard Generalized Markup/Language Extensible Markup Language) document type definition (dtd) for archival finding aids. Encoded Archival Description adoption includes two separate yet related processes: encoding and publication. Encoding is the process of tagging finding aids using the EAD dtd. This can be a straightforward task or can require a great deal of intellectual work to rework or extract information from a finding aid to match elements in the EAD dtd. Publication involves mounting marked-up finding aids on the World Wide Web. The publication process requires a higher level of technological skills than encoding, such as the ability to set the files up on a server, apply a search engine to the files, develop and link style sheets to finding aids, and write scripts to transform the native XML into HTML (Hypertext Markup Language) for viewing on a browser. Although browser functionality will alleviate this final step in the future, it is still often necessary to properly view the EAD finding aids.

Encoded Archival Description focuses on archival finding aids; however, archival finding aids can be defined broadly or narrowly. The original Encoded Archival Description Tag Library (Society of American Archivists and Office of the Library of Congress, 1998) defines a finding aid less inclusively and notes that the "term 'finding aid' traditionally encompasses a wide variety of tools to describe, control, and provide access to archives and manuscript collections, this encoding standard is primarily intended for a particular type of document known as inventories and registers" (p. 1).

This definition in the EAD Tag Library is derived from Miller's (1990) explication of inventories and registers in Arranging and Describing Archives and Manuscripts. Miller identifies inventories and registers as a specific document type that contains data elements such as introductory information, agency history/biography, scope and contents note, container lists, indexes, and appendices (pp. 93-98).

When we discuss finding aids here, we have adopted the definition and sense of the term employed by the Tag Library. To avoid confusion, we use access tools as the 
generic term that encompasses all types of archival descriptive surrogates (finding aids, registers, inventories, calendars, card catalogs, indexes, etc). At the same time, we acknowledge that the EAD dtd could be used with a wider variety of access tools; the pros and cons of EAD's flexibility have been addressed elsewhere (Shaw, 2001).

In this article, we report findings from a study on the diffusion and adoption of EAD within the U.S. archival community. Using Rogers' (1995) theory of the diffusion of innovations as a theoretical framework, we surveyed 399 archives and manuscript repositories that sent participants to EAD workshops from 1993-2002. Our findings indicated that EAD diffusion and adoption are complex phenomena. While the diffusion pattern mirrored that of MARC, overall adoption was slow. Only $42 \%$ of the survey respondents utilized EAD in their descriptive programs. Critical factors inhibiting adoption include the small staff size of many repositories, the lack of standardization in archival descriptive practices, a multiplicity of existing archival access tools, insufficient institutional infrastructure, and difficulty in maintaining expertise.

\section{Diffusion of Innovations and Encoded Archival Description Adoption}

Rogers (1995) proposed a comprehensive theoretical framework to explain how innovations spread over time and the factors that affect the speed and intensity of their spread. His book, Diffusion of Innovations identifies and examines innovations in a variety of fields including communications, public health, marketing, management, and sociology. Rogers' theory presents two core concepts: diffusion and adoption. Diffusion is the "process by which an innovation is communicated through certain channels over time among members of a social system" (p. 10). According to Rogers, diffusion is a complicated process in which cultural, technological, economic, and social readiness are often the deciding factors, rather than the relative merits of the innovation itself.

Adoption is a positive decision to employ an innovation; Rogers poses five characteristics of innovations that can be examined in relation to adoption: (a) relative advantage, (b) compatability, (c) complexity, (d) trialability, and (e) observability (pp. 15-17). Relative advantage is the extent to which an innovation is perceived as better than the idea it supersedes. Advantages can be measured in terms of the economic, social, or technological variables as well as through such measures as convenience or satisfaction. Compatibility is the degree to which an innovation aligns with such elements as current organizational practices and routines, organizational infrastructure, and resources. Complexity entails such diverse variables as the difficulty of the adoption process or the individual or organizational learning processes surrounding how to use an innovation. Trialability concerns the ability to experiment with an innovation before making a full commitment, and finally, observability is the degree to which the effects of an innovation are visible to others. As will be described below, we have adapted and applied each of these dimensions and operationalized them to be measured in specific ways.

Our study came about as a result of dissatisfaction with the current EAD literature, which fails to provide good analyses of diffusion or adoption patterns. This literature consists primarily of overviews of the history and evolution of EAD (e.g. Hensen, 1997; Kiesling, 1997; Pitti, 1997) and case studies (e.g., Bouché, 1997; Lacy \& St. Clair, 1997) describing individual experiences with EAD. These case studies are problematic because they are not generalizable. While they do discuss problems and adaptations of EAD, the case studies primarily reflect successful implementations and positive adoption decisions.

There have been three cross-institutional analyses of EAD adoption. Of those, two (Marshall, 2002; Roth, 2001) surveyed only EAD adopters. The third survey by Minks and Curtis (2002) provides the best description of EAD adoption and implementation. Roth (2001) surveyed current EAD adopters using the 47 archives and special collections linked to the EAD DTD homepage (http://jefferson.village.virginia.edu/ ead/sitesann.html). His focus was to examine implementation difficulties. Marshall's (2002) survey investigated how EAD affected the administration of archives and special collections as listed on the Society of American Archivists EAD Roundtable homepage in March 2000. Both of these surveys identified problems in the EAD implementation process. In Roth's study, a majority of the 31 respondents identified the lack of staff time to create and manage as well as the difficulty in learning the technologies to publish finding aids as the two major problems. Publishing online finding aids was a key issue because several software vendors no longer supported or had suspended sales of delivery systems. Of the 16 repositories responding to Marshall's survey, most perceived EAD as a better access tool, but found that incorporating EAD into organizational routines in terms of workflow and individual training was difficult. Most significantly, the archives and special collections primarily relied on internal funding to support EAD implementation and none had performed any cost/benefit analysis or examined the total costs of EAD adoption in detail.

Minks and Curtis (2002) surveyed 191 archival institutions internationally with 100 responses. Their sampling methodology also favored larger institutions that were more likely to adopt EAD. Minks and Curtis provided minimal interpretation, but the descriptive statistics they report illustrate the difficulty in EAD adoption. For example, although they found that $69 \%$ of the respondents were involved with EAD at some level, upon closer inspection $15 \%$ of those respondents were just in the planning stages and 16\% had only encoded finding aids without publishing any on the Web. Only 37\% of the respondents had actually completed the entire EAD implementation cycle of encoding and Web-based delivery. Their findings demonstrate the complexity of assessing the EAD adoption as well as moving between the different stages of the implementation process. 
The EAD adoption literature provides baseline indicators of diffusion patterns and the characteristics of adopting and nonadopting archives and special collections. The literature, however, does not place these findings in a broader theoretical or analytical framework. The literature on innovation, while not concerned with EAD, provides such a framework. Specifically, by examining the five characteristics of innovations cited by Rogers, a more nuanced as well as a clearer understanding of both EAD adoption and the difficulties of implementation can be reached.

\section{Methodology}

This study employed survey methodology. As noted above, our interest is in the adoption and diffusion of EAD by archival repositories and manuscript collections in the United States. Therefore, the archives or special collections formed the unit of analysis. The population for the survey was repositories that sent participants to the Research Libraries Group (RLG) and Society of American Archivists (SAA) EAD workshops from 1993-July 2002. This population was selected because this series of workshops was the major channel for diffusion of knowledge about EAD among the U.S. archival community. Although other EAD training options existed, the RLG and SAA workshops were the earliest and most consistently offered venues for EAD education. In total, this series of workshops enrolled 600 individual participants representing 399 archival and manuscript collections. One survey was sent to each of these 399 repositories. Several categories of noninstitutionally affiliated individuals, who enrolled in these workshops, such as students and consultants and archival institutions outside the United States, were excluded from the survey. Surveys were administered in the summer of 2002. Of the 399 questionnaires sent out, 135 or $34 \%$ were returned.

\section{Findings}

\section{Demographics}

Survey respondents were representative of the types of repositories in the initial sample surveyed. As shown in Figure 1,52\% of the survey sample and the respondents were colleges and universities. Proportional responses were received from other institutional sectors, such as government bodies, museums, and religious archives.

\section{Diffusion}

According to Rogers (1995), diffusion concerns the communication process and channels. We examined two primary measures, EAD education and the actual diffusion pattern, to test the strength of diffusion. These dimensions provided us with information concerning how EAD was diffusing on two levels. The first level was the macro level of the social system at large, i.e., the archival profession. The second level was the micro level, i.e., within the archival or
Surveyed $(\mathrm{N}=399)$

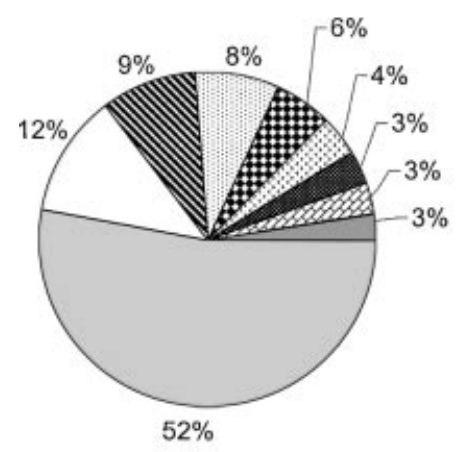

$\square$ College and University

$\square$ Governmental Body

\$ Museum

■Independent Library

\$ Non-profit Organization

문 Public Library

w For-profit Business

ø Religious Organization

$\square$ Unidentified

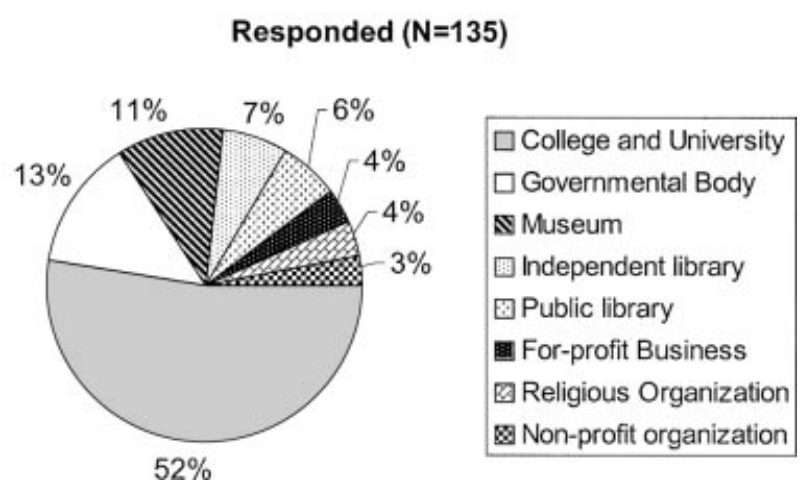

FIG. 1. Type of institution: Survey sample versus survey respondents.

manuscript repository. Taken together these perspectives provide some insight into the EAD diffusion model.

Diffusion patterns. Patterns of diffusion were measured by examining overall adoption trends in the social system as well as by studying internal patterns of adoption within repositories. At the macro level, the overall adoption rate was calculated and an analysis of the archives and special collections adopting EAD was done. On the micro level, individual archival and special collections programs, the number of encoders who were encoding, and the encoding rate were measured.

Of the 135 respondents, 57 or $42 \%$ identified themselves as EAD adopters. These EAD adopters were fairly stratified. Figure 2 provides a visualization of the diffusion pattern. Rogers points to the importance of a social system in the adoption decision (pp. 23-29). College and university archives comprise $62 \%$ of EAD adopters in our sample and were the group in which this innovation has taken hold most firmly. We did not investigate the reasons for this diffusion pattern; however, within this subcomponent of the larger archival community different incentives for adoption may be in place requiring further study. We can speculate on the factors contributing to the earlier and greater rate of adoption by college and university archives and special collections. These include a mandate to support the educational mission 


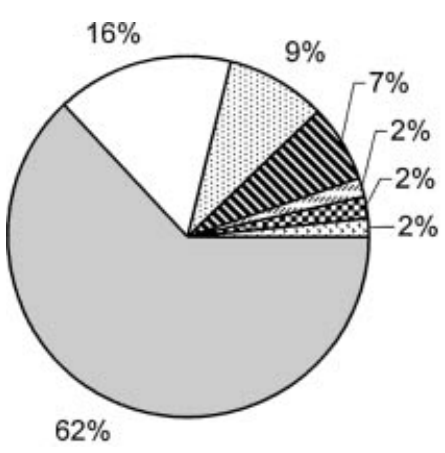

$\square$ College and University

口Governmental Body

EIndependent Library

sMuseum

巴Non-profit Organization

Qublic Library

QReligious Organization

FIG. 2. Encoded archival description (EAD) adopters by type of institution $(N=57)$.

of the larger institution by making archival resources more available for research and teaching and access to a stronger technological infrastructure through the existing organizational structure (most university archives and special collections are placed within the university library). This institutional placement may also facilitate diffusion of standards and technologies and provide experience through access to expertise in the related technological skills clustered in digital library services. This latter theory would confirm Fichman and Kemerer's (1997) findings on the importance of related knowledge and diversity of technological knowledge in lowering the barriers to knowledge acquisition to make way for adoption of new technologies. Interestingly, studies of the diffusion of MARC demonstrated a similar pattern of adoption by colleges and universities (Martin, 1994; Stout, 1984).

Even when archives and special collections have adopted $\mathrm{EAD}$, the number of encoders remained quite low. On average, EAD adopters have $1.94(n=53)$ people encoding finding aids. Professional archivists were also doing the majority of encoding; 18 repositories reported using at least 1 paraprofessional, 12 utilized students, and 2 clerical employees. The paucity of encoders may be related to the number of encoded finding aids. Among adopters, 36 archives and special collections encoded 40 or fewer finding aids and 18 encoded 41 or more. The mean number of published finding aids was 100; however, the median was only 30 demonstrating that there is a very large divergence in encoding with a few institutions marking up their entire set of finding aids while others made slower inroads into the encoding process. There was no relationship between the number of years since the initial EAD workshop was taken and the number of encoded or published finding aids.

\section{Encoded Archival Description Education}

Because the survey population was taken from participants in the RLG and SAA EAD workshops, we were not surprised to find that $67 \%(n=73)$ of respondents received their initial exposure to EAD training through formal workshops. In terms of later diffusion, however, the findings showed that archives and special collections have continued to send employees to EAD workshops rather than train them internally. Almost 56\% ( $n=63)$ still primarily used external workshops to educate staff about EAD. This lack of internalization of EAD expertise is problematic because it impedes EAD diffusion. Additionally, 22.9\% $(n=48)$ of the responding repositories specified that they had trouble maintaining EAD expertise. In comparison, we asked about MARC education and diffusion. We found that among the EAD adopters, $47 \%(n=22)$ received initial MARC training through workshops but now MARC knowledge and skills have been internalized. Among EAD adopters, 69\% received MARC training within their home collections through the archives or a library cataloger.

\section{Encoded Archival Description Adoption in the Archival Community}

Rogers (1995) defines adoption as the decision to make use of an innovation (p. 21). We examined adoption by utilizing his five characteristics of innovations (relative advantage, compatibility, complexity, trialability, and observability). While Rogers identifies these as characteristics of innovations, we adapted these concepts and compared the alignment among these characteristics of innovations with measurable variables of the archives or special collections unit. Of these concepts, relative advantage, compatibility, and complexity appeared to be the strongest indicators of EAD adoption.

\section{Relative Advantage}

As previously noted, the extent to which an innovation is perceived as better than the idea it supersedes is referred to as relative advantage. To address the issue of relative advantage, we compared and contrasted methods of publishing finding aids. Encoded archival description vies with and is attempting to supersede HTML and PDF (Portable Document Format) as a delivery mechanism for finding aids.

Table 1 shows that 72 repositories reported publishing finding aids on the Web utilizing HTML or PDF. Most interesting, over $50 \%$ of the EAD adopters also publish finding aids on the Web in HTML. They are also more likely than non-EAD adopters to publish finding aids. We did not inquire about the reasons for this redundancy, or why nonadopters of EAD also appear less likely to embrace any Web-based technologies for access.

Respondents were asked for comments at the end of the survey. Of the 13 comments that weighed the relative advantage of EAD and other finding aid publication options, 11

TABLE 1. Publication of finding aids in HTML and PDF.

\begin{tabular}{lccc}
\hline & EAD adopters & Non-EAD adopters & Total \\
\hline HTML & $37(51.4 \%)$ & $28(38.9 \%)$ & $65(90.3 \%)$ \\
PDF & $2(2.8 \%)$ & $1(1.4 \%)$ & $3(4.2 \%)$ \\
HTML and PDF & $3(4.2 \%)$ & $1(1.4 \%)$ & $4(5.6 \%)$ \\
Total & $42(58.3 \%)$ & $30(41.7 \%)$ & $72(100 \%)$ \\
\hline
\end{tabular}


TABLE 2. Types and frequencies of access tools by category of archival institution.

\begin{tabular}{|c|c|c|c|c|c|c|c|c|c|}
\hline Archival & $\begin{array}{l}\text { College or } \\
\text { university } \\
(N=71)\end{array}$ & $\begin{array}{l}\text { Government } \\
(N=18)\end{array}$ & $\begin{array}{l}\text { Museum } \\
(N=15)\end{array}$ & $\begin{array}{l}\text { Independent } \\
\text { library } \\
(N=9)\end{array}$ & $\begin{array}{l}\text { Public } \\
\text { library } \\
(N=8)\end{array}$ & $\begin{array}{l}\text { For-profit } \\
\text { business } \\
(N=5)\end{array}$ & $\begin{array}{l}\text { Religious } \\
\text { organization } \\
\quad(N=5)\end{array}$ & $\begin{array}{l}\text { Non-profit } \\
\text { organization } \\
\quad(N=4)\end{array}$ & $\begin{array}{c}\text { Total } \\
(N=135)\end{array}$ \\
\hline Finding aids & 71 & 17 & 14 & 9 & 8 & 3 & 5 & 4 & 131 \\
\hline MARC & 64 & 12 & 7 & 9 & 6 & 1 & 3 & 2 & 104 \\
\hline Online finding aids & 62 & 10 & 5 & 7 & 3 & 1 & 3 & 2 & 93 \\
\hline Online indexes & 30 & 9 & 3 & 2 & 2 & 4 & 3 & 1 & 54 \\
\hline Card catalog & 29 & 7 & 3 & 8 & 3 & 1 & 2 & 1 & 54 \\
\hline Calendar & 8 & 2 & 1 & 4 & 1 & 0 & 1 & 1 & 18 \\
\hline
\end{tabular}

did not think EAD offered any advantages over HTML or PDF. A typical comment was "We find that our HTML finding aids are as easy to or easier for researchers to use. No obvious advantages to EAD. Not sufficient evidence that it (EAD) meets the needs of users" (Survey 84). One respondent who identified the advantages of EAD noted: "I'm a big fan - I feel that EAD standardizes finding aids and therefore "socializes" researchers in archival context. SGML/XML negates migration / re-coding problems down the road. Open source code keeps costs down and applications flexible" (Survey 101).

\section{Compatibility}

Compatibility was examined through the use of four different dimensions: (a) descriptive practices, (b) institutional structure, (c) technological infrastructure, and (d) funding models for EAD implementation. These dimensions were selected because of our own interest in descriptive programs and as a result of the literature review. Institutional size had previously been identified as a factor in EAD adoption (Minks \& Curtis, 2002; Roth, 2001) and therefore we wanted to explore this in greater detail. Also, virtually all diffusion of innovation studies has found size to be a significant factor in adoption. Tatem (1998) argued that technological infrastructure and economic models were important factors in EAD adoption. Economic models for funding EAD were investigated because of Marshall's (2002) findings that archives and special collections were primarily relying on internal support to implement EAD. While these were not the only potential factors in EAD adoption, in our view, they were the most significant and required more analysis.

\section{Compatibility With Descriptive Practices}

Encoded Archival Description incorporates principles and standards such as the Anglo-American Cataloging Rules, MARC, and controlled vocabularies, and it is based on the standardization of the core archival access tool, the finding aid. Therefore, our assumption was that EAD adoption would be more likely in archives and special collections with expertise in using standards for archival description and those units that had standardized modern finding aids as their primary access tools because the actual implementation process would be easier. Implementation of EAD requires existing finding aids that lend themselves to SGML/XML mark-up, such as those that already mirror the EAD data structure. Compatibility with existing descriptive practices was operationalized in two ways. First, we determined the number and type of existing access tools within a repository, and second, by prior adoption of the MARC bibliographic format.

While all the archival agencies and manuscript repositories surveyed had finding aids, these were far from the only type of access tools present. On average, respondents had 3.37 different types of access tools for their collections. These categories of access tools are evidenced in Table 2. From this table, we have made several assumptions. First, the types of access tools reflect varying degrees of standardization. We also assume that these tools have been developed over time, and in some cases, these surrogates do not accurately reflect either the content or current structure of the collection. These factors make conversion into EAD possible, but often difficult and time consuming. Furthermore, many archives are reluctant to simply encode these surrogates without some degree of verification and reevaluation of the underlying collections because they recognize the surrogates are inaccurate (Meissner, 1997). Therefore, we think that these findings demonstrate a lack of compatibility between many of the current descriptive tools and EAD.

We hypothesized that prior adoption of MARC would be a factor in EAD adoption. Indeed, we found that use of the MARC format was linked to the adoption of EAD. The graph in Figure 3 shows that $96 \%$ of all EAD adopters are

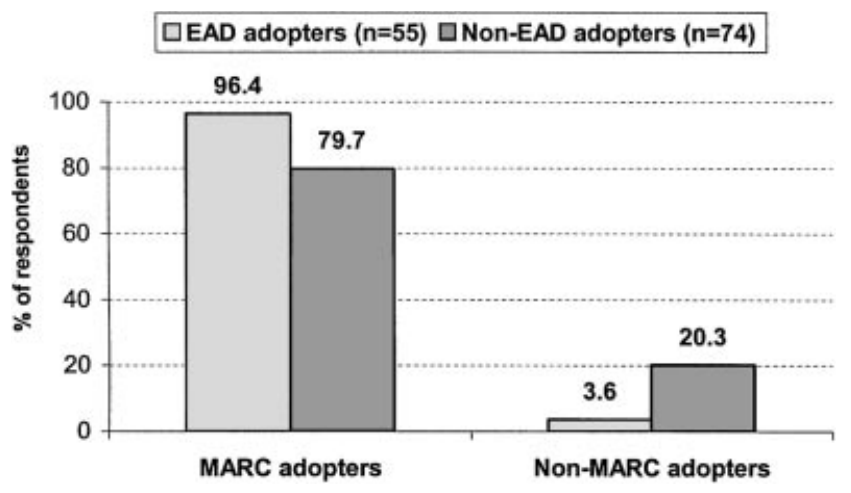

FIG. 3. Encoded Archival Description (EAD) and MAchine-Readable Cataloging (MARC) adoption. 
also MARC implementers whereas only $80 \%$ of the nonEAD adopters also use MARC. The results of the $\chi^{2}$ test showed a relationship between MARC and EAD adoption, $\chi^{2}(1,129)=7.63, p<.006$. Taken together, these findings suggest that prior adoption of MARC is positively related to EAD adoption.

\section{Compatibility With Institutional Structure}

Because size has long been a documented factor in adoption of innovations, we also operationalized size in three separate ways: the total number of collections, the extent (linear or cubic feet), and staff size. Prior studies have shown that institutional size is positively related to EAD adoption (Minks \& Curtis, 2002; Roth, 2001). In addition to our measures, these studies used various other approximations for size-specifically, total employees or students of the parent institution. We did not measure the size of the parent institution because we did not think size of the parent institution had anything to do with the amount of resources (money, staff) given to an archives or manuscript repository within the hierarchy. Very large institutions can have small and understaffed repositories.

Our analysis focused on two variables: the total number of collections and staff size. The findings showed a relationship between the number of collections and EAD adoption, $\left.\chi^{2}(3,100)=9.899, p<.019\right)$. The graph in Figure 4 also illustrates differences in EAD adoption patterns in very large and very small repositories. Responses from repositories with more than 2,000 collections indicated that 38.1 had adopted EAD. Among repositories with less than 220 collections, only 14.8 used EAD. Respondents with over 590 collections made up $61.9 \%$ of the EAD adopters in our sample.

\section{Staff Size}

Repository staff size was also a significant factor in EAD adoption, $\chi^{2}(3,127)=9.069, p<.028$. The median professional staff size for EAD adopters was four; double that of non-EAD adopters. Furthermore, the median number of

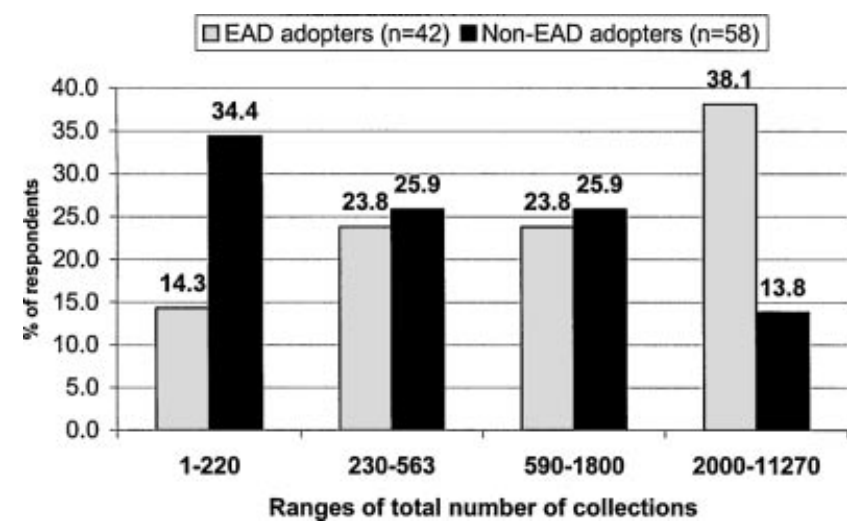

FIG. 4. Number of collections and Encoded Archival Description (EAD) adoption.

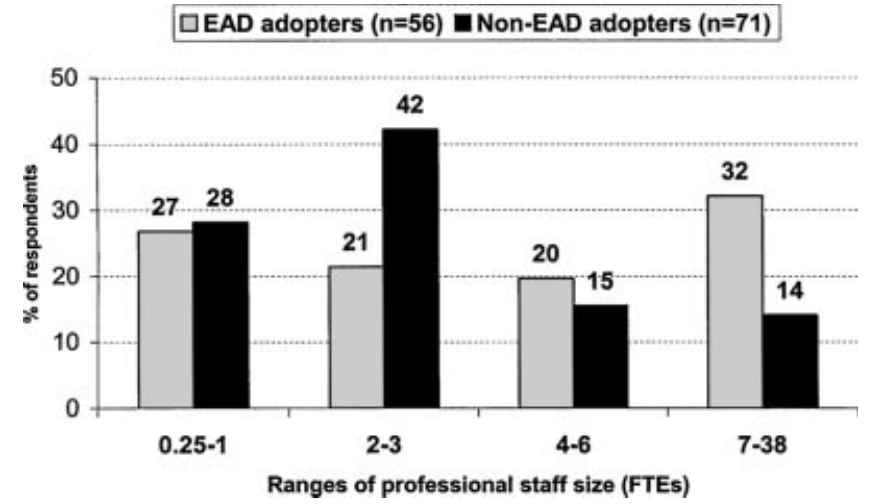

FIG. 5. Professional staff size and Encoded Archival Description (EAD) adoption.

total staff for EAD adopters was 10, over twice the median total staff size (4) for nonadopters (Figure 5).

We also assumed that consortia were a mechanism for lowering the barrier for EAD adoption. This was not so. There was no difference in median staff size for EAD adopters who were consortial participants and those who did not participate in consortia. The median professional staff size for consortial participants was also four fulltime equivalent (FTE) professional archivists.

\section{Technological Infrastructure}

Encoded Archival Description publication is dependent on access to a server, expertise in setting up XML files for delivery, and inserting the assorted scripts and middleware necessary to make encoded finding aids accessible. Therefore, we hypothesized that technological infrastructure would be a factor in EAD adoption. Technological infrastructure was measured in two ways: the presence of a technical support person on staff and server control. This hypothesis was rejected. Among EAD adopters, 27\% $(n=$ $35)$ had a technical support person and $33 \%(n=43)$ of the non-EAD adopters also had such a staff member. Neither EAD nor non-EAD adopters had a high degree of server control and overall only $25 \%(n=130)$ of the respondents maintained their own servers. Thirteen respondents also commented on the lack of technological support. One quotation illustrates what happens when internal technical support is lacking and the archives must compete with other units in an institution for these resources, "Lack of support from our systems staff due to other institutional priorities is a problem and will continue to be" (Survey 129).

\section{Funding Models}

Institutional funding models are important because they demonstrate the degree to which EAD encoding has been incorporated into daily practice as shown through a stable internal institutional funding line. Therefore, we asked how EAD encoding and delivery were funded. Thirty-two (57\%) out of $56 \mathrm{EAD}$ adopters indicated that they received grant 
TABLE 3. Number of published finding aids and grant funding.

\begin{tabular}{lcc}
\hline & \multicolumn{2}{c}{$\begin{array}{c}\text { Number of published } \\
\text { finding aids }\end{array}$} \\
\cline { 2 - 3 } & Average & Median \\
\hline Grant-funded adopter $(n=29)$ & 75.31 & 30 \\
Nongrant-funded adopter $(n=19)$ & 147.37 & 11 \\
\hline
\end{tabular}

funding, although they did not specify whether these grants were to support starting an EAD project or sustaining an ongoing EAD program. This result differs from Marshall's (2002) finding of reliance on internal funding.

We then examined the relationship between funding models and output in the form of published finding aids. This also served as an assessment of the institutionalization of EAD and the strength of its adoption. Interestingly, as indicated in Table 3, although the average number of finding aids published by archives and special collections without grant funding was larger than for those with EAD grants, the median number was greater for grant-funded repositories. The reason for this discrepancy was two nongrant-funded archives with large numbers of published finding aids. This indicated that while some institutionalization of funding for EAD encoding was occurring, repositories with funding were somewhat more likely to implement EAD and publish finding aids.

The $\chi^{2}$ tests found a relationship between both MARC adoption and professional staff size with EAD adoption; however, the direction of that relationship could not be determined from these tests. Because EAD adoption, the dependent variable, was binary, logistic regression was selected for the analysis. The ensuing regression model was constructed to estimate whether MARC adoption or staff size were positive predictors of EAD adoption. These became predictor variables to explain EAD adoption. The regression model was represented as follows: $\mathrm{y}=\beta_{0}+\beta_{1} \mathrm{x}_{1}+$ $\beta_{2} \mathrm{x}_{2}$ ( $\mathrm{y}=\mathrm{EAD}$ adoption; $\mathrm{x}_{1}=$ MARC adoption; $\mathrm{x}_{2}=$ professional staff size).

Table 4 presents the results of the logistic regression. Both MARC adoption and professional staff size were found to be statistically significant factors predicting EAD adoption. Based on Exp (B), the odds ratio estimates, MARC adoption increased the likelihood of EAD adoption by 5.998 times, when controlling for another factor, professional staff size. For every one fulltime equivalent increase in profes-

TABLE 4. Logistic regression analysis.

\begin{tabular}{lrcc}
\hline & B $^{\mathrm{a}}$ & $p$-value & Exp (B) \\
\hline MARC & 1.791 & $0.023^{*}$ & 5.998 \\
Professional Staff & 0.091 & $0.040^{*}$ & 1.095 \\
Constant & -2.317 & 0.788 & 0.099 \\
\hline
\end{tabular}

${ }^{\mathrm{a} B}$ indicates likelihood estimates. ${ }^{\mathrm{b}} \mathrm{Exp}(\mathrm{B})$ indicates odds ratio estimates. $* p<.05$. sional staff size, the likelihood of EAD adoption increased by 1.095 times, after controlling for MARC adoption. Consequently, the logistic regression analysis demonstrated that both MARC adoption and professional staff size were positive predictors of EAD adoption. Machine-readable cataloging adoption was a dichotomous variable and staff size was a continuous measure, therefore the strength of these predictors relative to each other cannot be judged. However, this test did show that archives that have previously adopted MARC and archives with a larger staff size were more likely to adopt EAD.

\section{Complexity}

Complexity concerns the difficulty in implementing or understanding an innovation. In EAD, complexity is demonstrated by the fact that encoding and delivery require different technological skill sets. Encoding requires knowledge of SGML/XML markup. Publication involves knowledge of such things as servers, style sheets, and scripting. Therefore, we measured the archives ability to accomplish these two components of EAD. Specifically, we examined encoding complexity in terms of the various software applications utilized for marking up finding aids. We also operationalized complexity in terms of the numbers of encoded versus published EAD finding aids, use of the EAD Cookbook (Prom, 2001), and finally outsourcing and participation in consortia.

\section{Encoded Archival Description Encoding Software}

Encoding requires a software selection decision. This is complex because of the variety of tools with vastly different functionalities available for EAD encoding. Options include XML editors, text editors, work processing applications, database software, and templates. Among the various types of applications, XML editors were the most commonly used, followed by text editors and word processors (Table 5).

The XML editors may be the most easy-to-use software for encoding because of their ability to automatically validate and display encoded finding aids. Interestingly, while 25 adopters used a single software application, the remaining 28 respondents utilized more than one type of software for

TABLE 5. Types of software used for EAD encoding.

\begin{tabular}{lcc}
\hline $\begin{array}{c}\text { Types of encoding } \\
\text { software }\end{array}$ & $\begin{array}{c}\text { Number of archives/ } \\
\text { special collections } \\
(N=53)\end{array}$ & $\begin{array}{c}\text { Number of archives/ } \\
\text { special collections } \\
(N=53)\end{array}$ \\
\hline XML editors & 33 & 62.3 \\
Text editors & 20 & 37.7 \\
Word processors & 18 & 33.9 \\
SGML editors & 10 & 18.9 \\
Databases & 9 & 16.9 \\
Web-based template & 6 & 11.3 \\
Automated encoding & 5 & 9.4 \\
\hline
\end{tabular}


TABLE 6. Number of encoding software applications used for Encoded Archival Description encoding.

\begin{tabular}{ccc}
\hline $\begin{array}{c}\text { Number of } \\
\text { encoding } \\
\begin{array}{c}\text { software } \\
\text { applications }\end{array}\end{array}$ & $\begin{array}{c}\text { Number of } \\
\text { archives/ } \\
\text { special } \\
\text { collections } \\
(N=53)\end{array}$ & $\begin{array}{c}\text { Number of } \\
\text { archives/ } \\
\text { special } \\
\text { collections } \\
(N=53)\end{array}$ \\
\hline 1 & 25 & 47.2 \\
2 & 15 & 28.3 \\
3 & 8 & 15.1 \\
4 & 4 & 7.5 \\
6 & 1 & 1.9 \\
Total & 53 & 100 \\
\hline
\end{tabular}

encoding (Table 6). These data indicate that there is no consensus as to the best software for encoding. The EAD adopters had difficulty in selecting appropriate types of applications and using them. Twenty-four EAD adopters commented on the need for better encoding tools. Comments highlighted the need for software that could be used by "nontechnical personnel" (Survey 24), and applications that were "adaptable to different workflows" (Survey 22). One respondent described the ideal encoding software as an "SGMLaware word processor with more functionality and less complicated ... more elegant [than] XML editors" (Survey 100).

\section{Encoding and Publication of Finding Aids}

Encoding and publishing finding aids are two separate operations requiring different skills and expertise. To assess complexity we asked people to rank aspects of EAD implementation. This did not generate sufficient responses to be useful. However, other measures demonstrated that publication was more difficult than encoding. First, the rate of Web publication of finding aids lagged behind encoding. Out of 52 EAD adopters, 33 encoded less than $10 \%$ of their finding aids. Of those 33, 18 published less than $10 \%$ of their encoded finding aids. As demonstrated in Table 3, the overall median numbers of published finding aids were relatively low, indicating that overall adoption is in the early stages. This discrepancy has been previously noted (Prom, 2002, p. 262) and apparently remains an issue. Second, a final open-ended question asked respondents to identify "the most important change that needs to occur in software connected to EAD." The comments overwhelmingly identified the need for better publication (37) over encoding (24) software as the major problem. As one respondent concisely put it, "Delivery needs to be simplified" (Survey 42). The gap between encoding and delivery was echoed in other comments, "The project to do so is currently in progress. Finding aids have been encoded, but the method of delivery is under development" (Survey 4). Other comments centered on both the need for an end-to-end, off-the-shelf software solution, and the need for more boxed systems that did not require knowledge of scripting, middleware, and server modifications.
TABLE 7. Uses of the EAD Cookbook.

\begin{tabular}{|c|c|}
\hline \multicolumn{2}{|c|}{$\begin{array}{l}\text { How do you use the Cookbook? (Select all that apply) } \\
\qquad(n=63)\end{array}$} \\
\hline To learn EAD & $44(69.8 \%)$ \\
\hline To learn XSL & $19(30.1 \%)$ \\
\hline As an XSL template & $15(23.8 \%)$ \\
\hline As an EAD template & $39(61.9 \%)$ \\
\hline \multicolumn{2}{|c|}{$\begin{array}{l}\text { Note. } \text { EAD }=\text { Encoded Archival Description; XSL }=\text { Extensible Style } \\
\text { Language. }\end{array}$} \\
\hline
\end{tabular}

According to Prom (2001), complexity was diminished with the use of support tools, such as the EAD Cookbook. His study, however, focused on archivists' use of the stepby-step implementation guidelines in the Cookbook. We found a much wider range of uses for the cookbook by EAD adopters as well as by nonadopters (Table 7). Of the 108 respondents to the question, "Do you use the EAD Cookbook?," 66 answered affirmatively. Among EAD adopters, $72 \%$ (41) used the Cookbook. Additionally, the uses of the Cookbook varied, ranging from an educational tool to a template for encoding and display.

\section{Outsourcing and Consortia}

Two means of alleviating the complexity of EAD are outsourcing the encoding of and participating in consortia to publish finding aids. Thirteen (23.6\%) of the EAD adopters used outsourcing to encode finding aids. More archives and manuscript collections used consortia to deliver finding aids, though. Among adopters, $31.4 \%$ of them delivered EAD finding aids only through consortia. This implies that publication or delivery of finding aids was more difficult than encoding. Table 8 shows the distribution of self-publication and consortial publication of EAD finding aids. There is a fairly even distribution of repositories that opted for consortial or self-publication. Notably, $11.7 \%$ of the archives provided multiple means of accessing their finding aids and another $25.5 \%$ just encode and neither self-published or utilized consortia.

\section{Trialability}

Trialability is the extent to which an organization can experiment with an innovation before making a full

TABLE 8. Publication of EAD finding aids.

\begin{tabular}{|c|c|c|c|c|}
\hline & & \multicolumn{2}{|c|}{ Consortial publication } & \multirow[b]{2}{*}{ Total } \\
\hline & & Yes & No & \\
\hline Self & Yes & $6(11.7 \%)$ & $16(31.4 \%)$ & $22(43.1 \%)$ \\
\hline Publication & No & $16(31.4 \%)$ & $13(25.5 \%)$ & $29(56.9 \%)$ \\
\hline Total & & $22(43.1 \%)$ & $29(56.9 \%)$ & $51(100 \%)$ \\
\hline
\end{tabular}


commitment. Encoded Archival Description provides little opportunity for experimentation. One means of EAD trialability was enrolling in an EAD workshop. As cited above, only $42 \%$ of EAD workshop participants went on to implement EAD in their collections. We surmise that people had several motives for taking the workshops other than implementing EAD. Rogers (1995) notes that there are five stages in the innovation decision process: knowledge gathering, persuasion, decision, implementation, and confirmation. Workshop attendance was one method of gathering information to make an informed decision on whether or not to implement EAD. Workshops also seemed to be a means for those in charge of descriptive programs to learn about this new technique. Both of these attempts at information gathering fit into Rogers' model.

The rates of encoding versus publishing mentioned above also demonstrated trialability. This may signal that many archives and manuscript collections were still in the decision stages concerning EAD adoption and that an actual adoption decision may still be made down the road once more experience with both encoding and delivery has been accumulated.

\section{Observability}

Observability is the degree to which the effects of an innovation are visible to others. We examined both the technical issues of finding aids publication and perceptions concerning how EAD was viewed. Tatem (1998) rightly notes, "An EAD finding aid that looks and acts like an HTML finding is unlikely to reflect the advantages of EAD" (p. 162). One disadvantage to doing server-side on-the-fly conversion of EAD/XML to HTML is that the end product does not appear to be much different than an HTML finding aid. This impression may be reinforced by the large number of EAD sites that do not offer the advantages of EAD finding aids such as searching ability (Kim, 2004). Unfortunately, our results on delivery methods were very low and so we are unable to report directly on observability. However, if one looks at the many emerging consortia (e.g., the Online Archive of California [California Digital Library, n.d.] or Research Libraries Group's Archival Resources [Research Libraries Group, n.d.]), one observes finding aids from many repositories. This could lead to the conclusion that EAD has been widely adopted by repositories throughout the United States. As our findings indicate, this is only partially true.

The comments provided information on perceptions of EAD, particularly whether it was seen as being compatible with existing practices and its degree of complexity. On descriptive practices one respondent noted, "Like all software, it needs to be easier to use. It's a long preparation-learning it, rethinking finding aids, new standard statements . . . but also frustrating to have to conform to rules $\&$ forms we did not help create-but an acceptable tradeoff. Takes a lot of time to straighten out details" (Survey 44). Another expressed, "If we did not have a sister institution with a large EAD staff, we would not have begun the complex \& costly process" (Survey 51). One nonadopter simply stated he or she was "unconvinced of the benefit to our institution" (Survey 109).

\section{Discussion}

Several of these findings require further discussion because of their implications. These findings are (a) size as a factor in EAD adoption, (b) compatibility with current descriptive programs and practices, (c) technological expertise, and (d) adopting but not diffusing EAD.

\section{Size as a Factor in Encoded Archival Description Adoption}

Our finding that collection and staff sizes were factors in EAD adoption is not surprising. Size has been linked to adoption in other types of diffusion studies (Kennedy, 1983). In the EAD case, the exact reason for this is not known. We can surmise that larger archival and special collections programs are better funded, and reside in larger institutions with greater and more diverse technological resources and expertise. A larger staff has the ability to dedicate more time to archival processing and achieving expertise in EAD encoding. Without the luxury of working with EAD for extended periods, it would be unlikely that individuals could build sufficient expertise to effectively use EAD. This finding held true whether or not repositories outsourced or participated in consortia. This is interesting, because consortia were organized with the intention of lowering the barriers for smaller archives. This does not appear to be happening - consortial participation also requires resource contributions by participants that are beyond the means of small repositories. Likewise tools, such as the EAD Cookbook, were aimed at facilitating EAD implementation in smaller archives, but this study demonstrated that smaller does not mean very small. As reported, four fulltime equivalent professional archivists appear to be the optimum needed to successfully implement EAD. This is very problematic for the archival profession. In the most recent survey of archivists (Society of American Archivists, 1996), 58\% of the respondents said that they worked in units with one to three FTE archivists. This means that a majority of archives will only be able to sustain an EAD program with great difficulty. Other models must be developed if EAD is to be extended to encode finding aids in these repositories.

\section{Descriptive Programs and Access Systems}

Compatibility issues were also key variables impeding EAD adoption. The multiplicity of descriptive tools in all responding archives and special collections and the various types of tools ranging from card catalogs to miscellaneous databases was a telling finding. As long as EAD is tied to the development of one type of descriptive tool (e.g., the finding aid), its utility will require retrospective conversion efforts that are potentially costly. As a result, the EAD adoption decision may be contingent on the decision to invest in the conversion of outmoded access tools to modern finding aids or updating analog finding aids into digital documents.

Prior adoption of MARC (and implicitly its underlying descriptive standards) as a predictor for EAD adoption was one of the most positive results of the survey. The 
MARC-EAD relationship may have a number of reasons. Adoption of MARC may have served to familiarize archivists and curators with related knowledge (descriptive standards) and created greater absorptive capacity. An additional hypothesis is that repositories that previously adopted MARC may have already faced the problem of inferior finding aids during that retrospective conversion process (e.g., Cloud, 1986). Therefore, the encoding of finding aids may require less reevaluation and verification of data and be less costly. Machine-readable cataloging constitutes a form of related technical knowledge (Fichman \& Kemerer, 1997) and as such, repositories using MARC would have developed mental models and frameworks for dealing with the technical and descriptive standards knowledge needed to implement MARC. These repositories would then have an easier time of identifying, learning the necessary skill sets, and applying them. This has been referred to as absorptive capacity (Cohen \& Levinthal, 1990) in innovation research.

\section{Leveraging Technological Expertise}

The issue of technological compatibility is of particular concern even though neither the level of technological expertise nor control over one's own server was shown to be a factor in EAD adoption. The lack of technological expertise reported in our findings is worrisome because it is an indicator of an endemic gap in archival knowledge that affects archivists' ability to function in an increasingly technological world. The degree to which archives and special collections do not control their own server is also not encouraging. These provide insight into the fairly universal lack of technological infrastructure in archives and manuscript repositories. This may account for the small number of archives who are able to leverage this knowledge by applying XML in other ways. While our study cannot verify this, the lack of server control in particular may be a reason for the different numbers of encoded and published finding aids. While the lack of a server relieves repositories of gaining and maintaining expertise in certain information technology tasks, it also makes them dependent on others to implement their EAD projects.

\section{Adopting Encoded Archival Description but Not Diffusing EAD Expertise}

As with many studies, this research opens up more questions than it answers. The most critical question for the archival community is "What is the level or critical mass of knowledge needed to sustain an innovation and maintain diffusion in a community?"

To answer this question we must define what constitutes EAD adoption. The questionnaire asked archives and special collections whether or not they had adopted EAD. In our analysis, we considered an EAD adopter as anyone who answered this question affirmatively. However, a number of those "adopters" are actually members of consortia that encode and deliver the finding aids for these repositories.
Knowledge of EAD for participation in the consortia is not always necessary. While these archival and manuscript collections have "adopted" EAD, the diffusion of knowledge concerning EAD is not as broad. The upside of this is that many repositories that were not able to sustain expertise in EAD were able to use outsourcing of encoding and consortia for publication. The downside is that any innovation needs to be sustained by a critical mass of people with knowledge of the innovation. Whether EAD continues to diffuse and sustain this critical mass is an issue. Maintaining, as well as extending, EAD knowledge is a critical factor in diffusion. The unanswered question is, "What level of knowledge or critical mass does the archival community need to sustain the EAD diffusion and adoption process?" Our survey results indicated that most EAD training was done outside of the archives. This led to the conclusion that repositories have not sufficiently internalized EAD expertise, a finding that stands in contrast to MARC where most archives and special collections have developed and sustained expertise internally.

\section{Conclusion}

This survey should be considered an early analysis of EAD diffusion and implementation. The results indicated that a majority of the respondents $(58 \%)$ have not adopted EAD. Reasons for the lack of adoption include an apparent size barrier, a lack of compatibility with existing descriptive practices, and the complexity of the technology. Surprisingly, technological infrastructure and the role of outsourcing and consortia were not significant factors. However, these and other factors will require monitoring and further research. At this point, EAD is neither a uniformly or universally adopted standard in the US. Whether the U.S. archival community's social system can sustain this innovation is still in question and whether EAD will be the technology through which archivists will create a union catalog bears watching.

\section{References}

Bouché, N.L. (1997). Implementing EAD in the Yale University library encoded archival description. American Archivist, 60(4), 408-419.

California Digital Library. (n.d.). Online archive of California. Retrieved June 30, 2005, from http://www.oac.cdlib.org

Cohen, W.M., \& Levinthal, D.A. (1990). Absorptive capacity: A new perspective on learning and innovation. Administrative Science Quarterly, $35(1), 128-152$.

Cloud, P. (1986). RLIN, AMC, and retrospective conversion: A case study. The Midwestern Archivist, XI(2), 125-134.

Fichman, R.G., \& Kemerer, C. (1997). The assimilation of process software innovations: An organizational learning perspective. Management Science, 43(10), 1345-1363.

Hensen, S.L. (1997). NISTF II and EAD: The evolution of archival description. American Archivist, 60(3), 284-296.

Kennedy, A.M. (1983). The adoption and diffusion of new industrial products. European Journal of Marketing, 17, 31-88.

Kiesling, K. (1997). EAD as an archival descriptive standard. American Archivist, 60(3), 344-354. 
Kim, J. (2004). EAD encoding and display: A content analysis. Journal of Archival Organization, 2(3), 41-55.

Lacy, M.A., \& St. Clair, M.A. (1997). EAD testing and implementation at the Library of Congress encoded archival description. American Archivist, 60(4), 420-435.

Marshall, J.A. (2002). The impact of EAD adoption on archival programs: A pilot survey of early implementers. Journal of Archival Organization, $1(1), 35-55$.

Martin, L.M. (1994). Viewing the field: A literature review and survey of the use of U.S. MARC AMC in U.S. academic libraries. American Archivist, 57(3), 482-497.

Meissner, D.E. (1997). First things first: Reengineering finding aids for implementation of EAD, encoded archival description at the Minnesota Historical Society. American Archivist, 60(4), 372-387.

Miller, F.M. (1990) Arranging and describing archives and manuscripts. Chicago: Society of American Archivists.

Minks, G.L.B., \& Curtis, L. (2002). The University of Tulsa digitization initiative: A blueprint for EAD implementation in the small academic library. Amigos Fellowship Final Report. Retrieved June 30, 2005, from http:// www.amigos.org/fellowship/2002_blueprint.pdf

Pitti, D.V. (1997). Encoded archival description: The development of an encoding standard for archival finding aids. American Archivist, 60(3), $268-283$.
Prom, C.J. (2001). Extending the capabilities of the EAD cookbook. OCLC Systems \& Services, 17(2), 89-95.

Prom, C.J. (2002). The EAD cookbook: A survey and usability study. American Archivist, 65(2), 257-275.

Research Libraries Group. (n.d.). Archival resources. Retrieved June 30, 2005, from http://www.rlg.org/en/page.php?Page_ID=120\&dataGo.x= $11 \&$ dataGo. $y=16$

Rogers, E.M. (1995). Diffusion of innovations. New York: Free Press.

Roth, J.M. (2001). Serving up EAD: An exploratory study on the deployment and utilization of encoded archival description finding aids. American Archivist, 64(2), 214-237.

Shaw, E.J. (2001). Rethinking the EAD: Balancing flexibility and interoperability. New Review of Information Technology, 7, 117-131.

Society of American Archivists. (1996). 1996 Salary survey. Chicago: Author.

Society of American Archivists and Office of the Library of Congress. (1998). Encoded archival description tag library: Version 1.0. Chicago: Society of American Archivists.

Stout, L., \& Baird, D. (1984). Automation in North American college and university archives: A survey. American Archivist, 47(4), 394-404.

Tatem, J.M. (1998). EAD: Obstacles to implementation, opportunities for understanding encoded archival description. Archival Issues, 23(2), $155-169$. 